\title{
/STUDIOMDA, UMA REFERÊNCIA NO PROJETO DE WAYFINDING
}

\section{/STUDIOMDA, A REFERENCE IN WAYFINDING DESIGN}

\author{
Gustavo Cossio, Me. \\ Instituto Federal de Santa Catarina - IFSC \\ e-mail: dsgcossio@gmail.com
}

Palavras-chave: sistemas de sinalização, wayfinding, design contemporâneo

\begin{abstract}
Resumo: A investigação trata sobre um escritório de design no sul do Brasil, especializado em sistemas de sinalização e wayfinding. A partir do reconhecimento por uma trajetória que contabiliza vinte anos de experiência, o objetivo é indicar a contribuição do /STUDIOMDA para uma cultura de design em âmbito regional, uma vez que desenvolve projetos de wayfinding para espaços e públicos diversos, entre ambientes residenciais, culturais e comerciais. A metodologia empregada para a realização da pesquisa consiste na história oral, com o testemunho pessoal da equipe, em entrevistas presenciais. Compreende-se que a longevidade do escritório se deve ao nível de excelência dos projetos que desenvolve e, portanto, constitui uma referência para os estudos sobre wayfinding.
\end{abstract}

Keywords: signage systems, wayfinding, contemporary design

Abstract: This research regards a design office in the south of Brazil, specialized in signage systems and wayfinding. Based on the acknowledgment of a trajectory that accounts for twenty years of experience, the aim is to point out the ISTUDIOMDA's contribution for a design culture at the regional level, once it develops wayfinding design for diverse spaces and audiences, among residential, cultural and commercial environments. The methodology used to conduct the research consists of oral history, with the personal testimony of the team, in face-to-face interviews. It is understood that the longevity of the office is due to the level of excellence of the projects that are developed and, therefore, it constitutes a reference for the studies on wayfinding.

\section{Introdução}

Este artigo apresenta o estudo sobre um escritório de design que contabiliza uma trajetória de vinte anos em projetos de sistemas de sinalização e wayfinding. A empresa começou a atuar em 1993, e tornou-se /STUDIOMDA em $1996^{1}$. Com

\footnotetext{
${ }^{1}$ Nascida em Curitiba-PR em 1970, a sócia-diretora Luciana Mattiello cursou Arquitetura e Urbanismo na Universidade Federal do Rio Grande do Sul - UFRGS, onde se formou em 1993. É especialista em Design Estratégico e em Design Gráfico, pela Unisinos. O nome do escritório surge de uma abreviação para
}

atuação a partir do estado do Rio Grande do Sul, o /STUDIOMDA wayfinding design desenvolve projetos para diversos setores, entre condomínios residenciais, espaços comerciais e culturais. Logo, espera-se oportunizar uma reflexão sobre a contribuição do /STUDIOMDA para uma cultura de projeto no sul do país.

Este trabalho integra uma pesquisa sobre história do design em âmbito regional, na qual são privilegiados os atores sociais que contribuem para

\footnotetext{
"Mattiello Design e Arquitetura".
}

Realização:
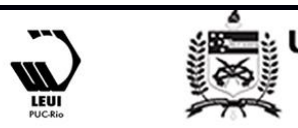


\section{$16^{\circ}$ \\ ERGODESIGN USIHC CINAHPA}

a consolidação de uma cultura de design local, do período de industrialização ao cenário contemporâneo. Os resultados são publicados sistematicamente no Congresso Brasileiro de Pesquisa e Desenvolvimento em Design - P\&D Design e na Revista Estudos em Design².

De modo a contextualizar o campo de atuação do /STUDIOMDA, é traçado um breve panorama sobre design de sinalização e wayfinding, com base em uma revisão de literatura. Para o levantamento sobre os aspectos biográficos, empregou-se o método da história oral, que consiste na realização de entrevistas com pessoas que fizeram parte, presenciaram os acontecimentos ou participaram da conjuntura (ALBERTI, 2007).

Contou-se com o depoimento dos seguintes integrantes da equipe: Luciana Mattiello, arquiteta e sócia-diretora, Manuela Medeiros, diretora administrativa, Gustavo Bassani, arquiteto e gerente de processos, e Eissom Fangueiro, designer. Além destes, outros três designers compõem a equipe. Assim, a análise é realizada a partir do olhar privilegiado dos profissionais, com depoimentos registrados em áudio e posteriormente transcritos ${ }^{3}$.

\section{Desenvolvimento}

\subsection{Apontamentos sobre wayfinding}

Faz-se necessário aprofundar a compreensão acerca de wayfinding, pois a orientação espacial (fluxo) constitui fator determinante na experiência do público. As características de cada um dos espaços, ou seja, as características arquitetônicas, a distribuição dos elementos expositivos e de sinalização, a circulação e os fluxos interferem na localização dos usuários. Nesse contexto, o sistema de wayfinding deve considerar o posicionamento e a diagramação das informações, o uso de cores e

\footnotetext{
${ }^{2}$ Os estudos anteriores trataram das trajetórias e projetos desenvolvidos pelos designers Norberto Bozzetti, Antônio Endler, Manlio Gobbi, a dupla José Carlos Mário Bornancini e Nelson Ivan Petzold, e os escritórios Verdi Design e Bertussi Design.

${ }^{3}$ As entrevistas foram realizadas em abril de 2016, na sede do escritório em Porto Alegre-RS.
}

$16^{\circ}$ Ergodesign - Congresso Internacional de Ergonomia e Usabilidade de Interfaces Humano Tecnológica: Produto, Informações Ambientes Construídos e Transporte

$16^{\circ}$ USIHC - Congresso Internacional de Ergonomia e Usabilidade de Interfaces Humano Computador

CINAHPA | 2017 - Congresso Internacional de Ambientes Hipermídia para Aprendizagem. de materiais para criar espaços funcionais, confortáveis e cativantes, que oportunizem uma experiência significativa aos ocupantes.

O termo wayfinding foi usado, pela primeira vez, em 1960, por Lynch (1997) considerando os mapas, as ruas, a sua numeração, os sinais direcionais e outros elementos como auxiliares na busca ou como a "maneira de se encontrar" no espaço urbano. O seu trabalho é baseado no conceito da orientação espacial e o seu prérequisito é a capacidade que o ser humano tem para desenvolver o mapa cognitivo, o qual o autor denomina "imagem". Posteriormente, em 1984, Arthur e Passini (1992) articularam o moderno conceito de wayfinding como um processo dinâmico para solucionar os problemas de mobilidade das pessoas no ambiente. No mesmo contexto, Berger (2005) emprega o termo wayfinding como orientação espacial ou a capacidade do ser humano de navegação. $\mathrm{O}$ autor ressalta que

wayfinding não trata apenas de 'placas'. Trata sobre navegação em espaços complexos em uma integração de todas as formas de comunicação visual. Além da sinalização, os componentes de wayfinding podem incluir esculturas, marcos ou ícones, efeitos especiais de iluminação, estruturas arquitetônicas, materiais, cores, tecnologia e projeções de vídeo. Esses componentes devem estar integrados com as plantas-baixas e o orçamento do projeto em sua etapa inicial (BERGER, 2005, p. 110, tradução livre do autor).

Nesse aspecto, os itens mais importantes para um projeto de wayfinding são o planejamento espacial e a comunicação. A interação de ambos consiste na ordenação das informações para a tomada de decisão dos usuários, em um relacionamento dinâmico com o espaço, onde são levados em conta aspectos como percepção ambiental, circulação, fluxos, referências, marcos e, acima de tudo, a informação (VELHO, 2007).

Segundo Locatelli (2007), temos dois grupos de fatores relacionados ao wayfinding: os contextuais e os composicionais. Os fatores contextuais são variáveis relacionadas ao ambiente, que influenciam na orientação espacial, sendo que as principais são: a presença de marcos ou pontos de 


\section{$16^{\circ}$ \\ ERGODESIGN USIHC CINAHPA}

referência, os dispositivos de sinalização e configuração espacial, ou seja, o sistema de relações espaciais e as suas formas, as organizações e os sistemas de circulação. Já os fatores composicionais são variáveis relacionadas ao indivíduo e que parecem influenciar o comportamento dos usuários, de acordo com as suas características individuais. São elas: percepções, expectativas e avaliações quanto a espaços, levando em conta, entre outros elementos, faixa etária, gênero, cultura, nível socioeconômico, estilo de vida, experiência passada e grau de familiaridade com o espaço.

Ao refletir sobre sua área de atuação, a equipe do /STUDIOMDA salienta que, para o público geral, o termo 'sinalização' está associado às placas de rua. Então, em uma intenção didática, a estratégia consiste em mostrar exemplos de projetos, a partir de uma apresentação e das informações disponíveis pelo website da empresa, no qual é mantido um blog ${ }^{4}$. Os projetistas afirmam que os autores divergem sobre o conceito de wayfinding, e retomam a definição de Lynch (1997): “a sinalização é saber onde se está e para onde se vai e wayfinding é tudo o que envolve essa modalidade projetual"5 (BASSANI; FANGUEIRO, 2016).

A sócia-diretora acrescenta que costumam explicar a dimensão qualitativa do projeto, as suas vantagens, e o quanto pode gerar valor para o empreendimento. Mattiello (2016) esclarece que, além da sinalização, pode-se fazer uma ambientação - que talvez dispense uma placa na

\footnotetext{
${ }^{4}$ Ver <www.studiomda.com.br/blog > Acesso em 20 de fev. de 2017.

${ }^{5}$ A equipe destaca que alguns autores e profissionais denominam design gráfico-ambiental o que o escritório denomina wayfinding design, considerando-os sinônimos. Para outros, o wayfinding é concebido como um tema comum às habilitações do design gráficoambiental. O /STUDIOMDA compreende o design gráfico-ambiental como um trabalho de ambientação, que também informa, expõe, orienta e sinaliza. Há também os estudiosos que restringem o conceito de wayfinding a uma etapa do projeto, na qual, a partir do estudo dos fluxos e identificação dos pontos de decisão, marca-se a localização de placas em uma planta-baixa (FANGUEIRO, 2016).
}

$16^{\circ}$ Ergodesign - Congresso Internacional de Ergonomia e Usabilidade de Interfaces Humano Tecnológica: Produto, Informações Ambientes Construídos e Transporte

$16^{\circ}$ USIHC - Congresso Internacional de Ergonomia e Usabilidade de Interfaces Humano Computador

CINAHPA | 2017 - Congresso Internacional de Ambientes Hipermídia para Aprendizagem.

parede, substituindo-a por uma pintura ou algum elemento especial, que sinalize de forma indireta.

\subsection{O percurso do /STUDIOMDA}

A borboleta Monarca é distinta não só por seu belo padrão de cores, mas também por seu misterioso senso de orientação. Milhares delas migram no inverno para um destino específico sem nunca ter feito o percurso antes. Isso é o que buscamos com nossos projetos: permitir que as pessoas entendam e utilizem ambientes sem precisar conhecê-los. - Texto de apresentação do /STUDIOMDA. Grifos mantidos conforme o original.

Mattiello (2016) conta que, inicialmente, os projetos eram desenvolvidos com base em sistemas modulares de sinalização, importados por uma empresa situada no Rio de Janeiro ${ }^{6}$. Passou então a estruturar métodos de trabalho a partir de desdobramentos da metodologia da arquitetura, procurando entender como proceder caso o suporte daquela empresa terminasse.

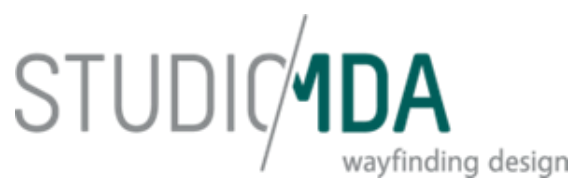

Figura 1 - A identidade visual do /STUDIOMDA.

Entre os primeiros projetos desenvolvidos, trabalharam com a Calçados Beira Rio, de Novo Hamburgo, com a Irving Tools, empresa de ferramentas da cidade de Carlos Barbosa, com o Blue Tree Towers, hotel em Porto Alegre, e com o Museu de Arte do Rio Grande do Sul - MARGS, que utiliza o sistema de sinalização modular até os dias atuais. O sistema do MARGS é interessante, pois no diretório ${ }^{7}$ utilizaram réguas que possibilitavam a troca conforme a exposição, o que possibilitou flexibilidade e praticidade para o museu ${ }^{8}$.

\footnotetext{
${ }^{6}$ Os sistemas modulares eram produzidos pela empresa americana APCO - Architectural Sign Systems, que segue atuante.

${ }^{7} \mathrm{O}$ diretório é um tipo de elemento de sinalização.

${ }^{8}$ Embora esses projetos iniciais tenham sido bemsucedidos, a equipe destaca as limitações do sistema modular, pois na época era complexo importar o material. Havia muitos problemas de alfândega no país,
}

Realização:

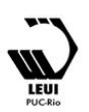




\section{$16^{\circ}$ \\ ERGODESIGN USIHC CINAHPA}

Nessa fase, Mattiello (2016) explica que havia muitos segmentos no escritório: arquitetura, sinalização, arquitetura comercial, identidade visual e design gráfico. Uma vez que os designers passaram a ingressar na equipe, tomaram a decisão de não mais realizar projetos em arquitetura, pois estavam especializados em sinalização, e julgaram que valia a pena seguir no design ${ }^{9}$. A diretora ressalta que o ingresso dos designers possibilitou o entendimento sobre tópicos como tipografia, pictogramas, e todos os elementos integram o aporte desses profissionais.

Após os sistemas modulares, passaram a focar em projetos personalizados, sendo que os arquitetos de Porto Alegre começaram a buscar parceria com o escritório para a sinalização dos empreendimentos que realizavam. Salienta-se o trabalho conjunto com o arquiteto Pedro Simch, com quem recentemente a equipe desenvolveu o projeto de wayfinding para o Grupo Dimed e seus centros de distribuição, em Eldorado do Sul-RS. Outra parceria de longa data foi com o arquiteto Sérgio Montserrat, com quem a equipe ressalta ter aprendido sobre modulação.

Em seguida, passaram a aperfeiçoar o detalhamento técnico, em uma colaboração contínua entre arquitetos e designers. Ao final dos anos 1990, começaram a trabalhar com a Cia. Zaffari. Nessa época, sinalizaram a Clínica Visão, cujo projeto continua instalado até os dias atuais. Também desenvolveram o sistema para o Moinhos Shopping e o Hotel Sheraton ${ }^{10}$. Foi um trabalho de

o material atrasava e perdia-se os prazos. Ainda assim, ressalta-se que o sistema permite explorar a criatividade e é bastante flexível, e representou uma motivação para o escritório seguir na área do design de sinalização.

${ }^{9}$ Sobre essa transição a partir da arquitetura, Mattiello (2016) afirma que estava um pouco insatisfeita com os projetos de longa duração e de grandes dimensões. Em 2016, de modo a ampliar as perspectivas de atuação, o /STUDIOMDA passou a operar também na Bélgica, com sede próxima à capital, Bruxelas.

${ }^{10} \mathrm{O}$ primeiro sistema de sinalização para o Moinhos

Shopping foi inspirado na identidade visual desenvolvida por Norberto Bozzetti. O designer e professor Bozzetti atua desde os anos 1960, sendo um pioneiro do design gráfico no sul do país, onde desenvolve projetos de identidade visual para diversos $16^{\circ}$ Ergodesign - Congresso Internacional de Ergonomia e Usabilidade de Interfaces Humano Tecnológica: Produto, Informações Ambientes Construídos e Transporte

$16^{\circ}$ USIHC - Congresso Internacional de Ergonomia e Usabilidade de Interfaces Humano Computador

CINAHPA | 2017 - Congresso Internacional de Ambientes Hipermídia para Aprendizagem.

grande vulto, quando o /STUDIOMDA começou a ser reconhecido, pois os projetos de sinalização ainda eram incipientes em Porto Alegre ${ }^{11}$.

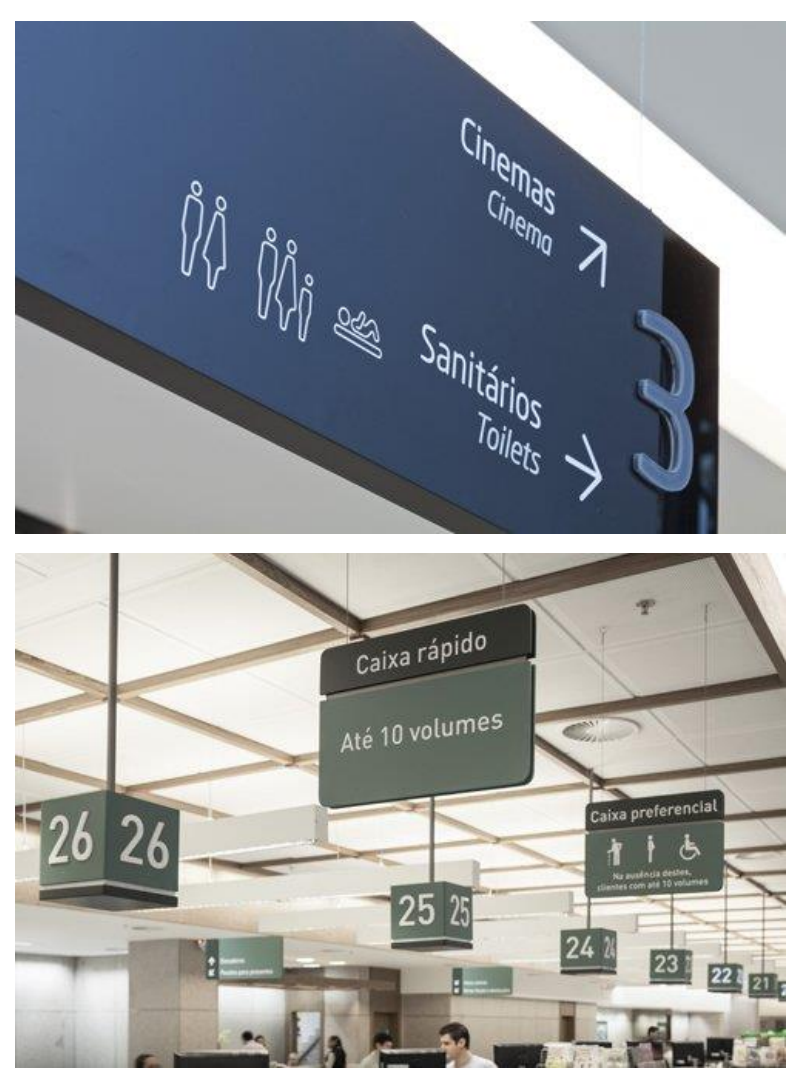

Figura 2 - Acima, detalhe do projeto para o Moinhos Shopping. Abaixo, parte do projeto para o Hipermercado Zaffari Wallig Fonte: arquivo /STUDIOMDA (2017).

No que se refere à contribuição para a consolidação de uma cultura local de projeto, Mattiello (2016) cita que o escritório se depara com esse desafio diariamente:

Fazemos trabalhos conceituais que exigem processo, tempo e envolvimento, pessoas talentosas e o

setores. O projeto atual para o Moinhos Shopping também foi feito pelo /STUDIOMDA, sendo um redesign do anterior, e constitui a primeira sinalização bilíngüe que desenvolveram.

${ }^{11}$ Os demais clientes do escritório incluem CFL Construções, Galmo Engenharia e Construções, Unimed, Universidade Feevale, Phorbis, Sicredi, Univates, Melnick Even, Softplan e Laboratórios Weinmann.
Realização:
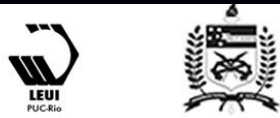


\section{$16^{\circ}$ \\ ERGODESIGN USIHC CINAHPA}

$16^{\circ}$ Ergodesign - Congresso Internacional de Ergonomia e Usabilidade de Interfaces Humano Tecnológica: Produto, Informações Ambientes Construídos e Transporte

$16^{\circ}$ USIHC - Congresso Internacional de Ergonomia e Usabilidade de Interfaces Humano Computador

CINAHPA | 2017 - Congresso Internacional de Ambientes Hipermídia para Aprendizagem. investimento em idéias e criação. A decisão de ir além da meta financeira se torna difícil para a manutenção de uma empresa no mercado, pois pode parecer um pouco mais romântico. Porém, todas as pessoas que trabalham no /STUDIOMDA acreditam nesse tipo de valor. É aí que estamos situados: não trabalhamos fazendo qualquer projeto, em poucos dias [...] Nossos projetos passam por muitas revisões e muitos detalhes, para que no final o resultado saia de acordo com o que pretendíamos (MATTIELLO, 2016).

Em seu comentário sobre o mercado, Bassani (2016) esclarece sobre a necessidade de maior aprofundamento para a realização de projetos. $\mathrm{O}$ gerente explica que para obter sucesso, o planejamento é a chave para uma boa execução. No entanto, para determinados profissionais, usualmente o tempo de planejamento é sacrificado, pois parte-se mais rapidamente para a execução, com o resultado ficando à margem do esperado. Portanto, Bassani (2016) defende a necessidade de um tempo mínimo de projeto, ainda que o mercado seguidamente responda que algum profissional desenvolve o mesmo trabalho mais rapidamente. Porém, o projetista salienta que os resultados serão diferentes.

Já sobre as atribuições da equipe, Mattiello (2016) destaca o perfil do /STUDIOMDA: todos os integrantes fazem parte de todo o processo. Os profissionais participam do briefing, desenvolvem os projetos e coordenam os processos internos e de relação com o cliente. Não há uma separação entre quem se ocupa do conceito, quem desenvolve, e alguém que acompanha. Como se trata de um pequeno escritório, a diretora considera este um ponto positivo: todos tem conhecimento dos projetos que estão em andamento, contribuem com opiniões sobre o que está sendo feito e auxiliam a resolver determinado problema.

Essas competências refletem em uma metodologia própria para o desenvolvimento de projetos de wayfinding. Nesse aspecto, Bassani e Medeiros (2016) destacam que investem no briefing, quando buscam obter o máximo possível de informações e socilitam o projeto arquitetônico. Acrescentam que, ao visitar a obra, a equipe formata a própria impressão sobre as necessidades. Então, passam para o anteprojeto que, após aprovação do cliente, se encaminha para o projeto executivo, com o detalhamento de todas as peças. Finalmente, validam as alternativas propostas na instalação.

Sobre o método que elaborou ao longo dos anos, Mattiello (2006) afirma que ocorrem alguns desvios de rota e que podem ser produtivos. Muitas vezes, o que não é dito é mais importante do que as informações que são formalmente repassadas para a equipe. Torna-se estratégico observar além do óbvio, no sentido que pode-se mostrar caminhos diferentes do esperado, e é aí que o projeto ganha qualidade e diferença porque são buscadas soluções que estão de acordo com a interpretação do briefing, o que geralmente surpreende o usuário e o cliente.

A respeito das particularidades do briefing para projetos de wayfinding, a equipe cita o conceito do empreendimento, as características do público, aspectos da interação do usuário com o espaço arquitetônico, além de orientação, pontos de acesso, segurança, e necessidades específicas de carga e descarga. $\mathrm{O}$ escritório possui experiência em simplificar as questões de funcionamento e operação de qualquer tipo de empreendimento. Quando participam desde a obra, conseguem atuar na raiz da questão e simplificar o processo. A situação de corrigir falhas com a sinalização não chega à equipe, mas sim utilizam a sinalização como um complemento para o funcionamento dos espaços (BASSANI; FANGUEIRO; MEDEIROS, 2016).

Durante a fase de anteprojeto, a equipe informa que são construídos protótipos sempre que possível, o que auxilia a equipe e o entendimento por parte do cliente ${ }^{12}$. Nesse sentido, segundo os profissionais, por mais que um modelo tridimensional via software seja pertinente, é quando o cliente tem contato com o material, podendo tocar e analisar as dimensões, que aprofunda-se a compreensão sobre o trabalho.

\footnotetext{
${ }^{12}$ Quando estão realizando os desenhos iniciais, estudando proporções dos elementos e tamanhos de texto, costumam construir mocapes, para testes que antecedem a apresentação do protótipo ao cliente.
}

Realização:

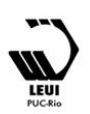




\section{$16^{\circ}$ \\ ERGODESIGN USIHC CINAHPA}

$16^{\circ}$ Ergodesign - Congresso Internacional de Ergonomia e Usabilidade de Interfaces Humano Tecnológica: Produto, Informações Ambientes Construídos e Transporte

$16^{\circ}$ USIHC - Congresso Internacional de Ergonomia e Usabilidade de Interfaces Humano Computador

CINAHPA | 2017 - Congresso Internacional de Ambientes Hipermídia para Aprendizagem.

\section{Considerações Finais}

Com base neste estudo, compreende-se que, no projeto de wayfinding, desenvolve-se a estratégia de circulação, estuda-se o ambiente e o público que irá utilizá-lo. De modo a destacar a interface entre arquitetura e design nas palestras que profere em universidades, a diretora do escritório costuma exemplificar com o aeroporto. Sem a sinalização não é possível circular, acessar o portão de embarque e localizar o voo. Ou seja, a sinalização tem um papel fundamental em vários edifícios $\mathrm{e}$ espaços urbanos.

O sistema de sinalização é uma parte do desenvolvimento do trabalho do /STUDIOMDA, sendo que a essência do projeto é outra. Em consonância com o que postulou Berger (2005) anteriormente, a intervenção é muito mais estratégica e de inteligência do que apenas projetar placas. Assim, o objetivo é conferir identidade aos espaços, valorizando os aspectos comunicacionais dos ambientes. Nesse sentido, é possível estabelecer um nexo com o que ensina Niemeyer (2008): o objetivo do design é resolver os problemas de diálogo com os outros e consigo mesmo. No caso dos projetos de wayfinding realizados pelo /STUDIOMDA, percebe-se que a tarefa é resolver o diálogo entre as pessoas e os espaços nos quais circulam.

Ao traçar o perfil profissional almejado para integrar a equipe, com ênfase na sensibilidade para tornar o ato projetivo mais humano, pontua-se a dimensão ética do design. Assim, o escritório opta por se manter em uma linha de pensamento que se faz necessária diante do contexto atual, de crise socioeconômica e de relações soltas nas dimensões de tempo e espaço.

Em última análise, compreende-se que a pertinência do projeto de wayfinding reside em humanizar os ambientes, de modo que as pessoas encontrem o caminho certo, aprendam e sintam-se bem nos espaços. Desse modo, valida-se a hipótese inicial: a longevidade do escritório se deve ao nível de excelência dos projetos que desenvolve, tendo a humanização dos espaços como elemento norteador.

\section{Bibliografia}

ALBERTI, V. Manual de História Oral. Rio de Janeiro: FGV, 2007.

ARTHUR, P.; PASSINI, R. Wayfinding People, Signs, and Architecture. New York: McGrawHill, 1992.

BASSANI, G. Sobre o escritório e projetos. Entrevistas ao autor. Porto Alegre, abril de 2016.

BERGER, C. M. (Org.). Wayfinding: designing and implementing graphic navigational systems. Hove: Rotovision, 2005.

FANGUEIRO, E. Sobre o escritório e projetos Entrevistas ao autor. Porto Alegre, abril de 2016.

\section{LOCATELLI, L. Orientação Espacial e}

Características Urbanas. Dissertação de mestrado. Programa de Pós-graduação em Planejamento Urbano e Regional; Universidade Federal do Rio Grande do Sul - PROPUR/UFRGS, 2007.

LYNCH, K. A Imagem da Cidade. São Paulo: Martins Fontes, 1997.

MATTIELLO, L. Sobre o escritório e projetos. Entrevistas ao autor. Porto Alegre, abril de 2016.

MEDEIROS, M. Sobre o escritório e projetos. Entrevistas ao autor. Porto Alegre, abril de 2016.

NIEMEYER, L. Design Atitudinal: uma abordagem projetual. In: Design Ergonomia Emoção. MONT'ALVÃO, C.; DAMAZIO, V. (Orgs.) Rio de Janeiro: Mauad X FAPERJ, 2008.

VELHO, A. L. O. L. O design de sinalização no Brasil: a introdução de novos conceitos de 1970 a 2000. Dissertação de mestrado. PUC-Rio, Rio de Janeiro, 2007.
Realização:

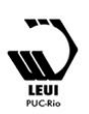

